\title{
Improving the Performance of Polysulfone-nano ZnO Membranes for Water Treatment in Oil Refinery with Modified UV Irradiation and Polyvinyl Alcohol
}

\author{
Malikhatul Hidayah ${ }^{1,3}$, Tutuk Djoko Kusworo ${ }^{1,2^{*}}$, Heru Susanto ${ }^{1,2}$ \\ ${ }^{1}$ Department of Chemical-Engineering, Faculty of Engineering, Diponegoro-University, Jl. Prof. H. Soedarto, S. H., 50275 \\ Tembalang, Kota Semarang, Jawa Tengah, Indonesia \\ ${ }^{2}$ Membrane Research Center (MeRC), Center of Exellence Building, Diponegoro University, Jl. Prof. H. Soedarto, S.H., 50275 \\ Tembalang, Kota Semarang, Jawa Tengah, Indonesia \\ ${ }^{3}$ Chemistry Department, Faculty of Science and Technology, Walisongo State Islamic University, Jl. Prof. Hamka, 50181 Jawa \\ Tengah, Ngaliyan Semarang, Indonesia \\ *Corresponding author, e-mail: tdkusworo@che.undip.ac.id
}

Received: 13 August 2020, Accepted: 04 December 2020, Published online: 27 October 2021

\begin{abstract}
Refinery wastewater is generated from the process of refining large amounts of oil. Oil refined wastewater contains micron-scaled emulsion droplets, and sub-micron droplets that are difficult to remove from water, which poses problems for researchers. Membrane technology is widely used in water treatment because it is very selective and effective in the filtration process. This research focuses on oil refinery water treatment using polysulfone (PSF) membrane ZnO nano composites modified with ultraviolet (UV) irradiation and polyvinyl alcohol. This membrane was prepared using the dry / wet phase inversion method. Then-the membrane was modified using UV irradiation and coated with polyvinyl alcohol (PVA). PSF-nano ZnO modifications have an impact on membrane performance; UV irradiation showed an increase in the value of membrane pure water flux from $4.5 \mathrm{Lm}^{-2} \mathrm{~h}^{-1}$ to $5.7 \mathrm{Lm}^{-2} \mathrm{~h}^{-1}$. However, after UV irradiation, the rejection value decreased after UV irradiation, whereas the presence of PVA as a coating agent increased the rejection value to $77.2 \%$ for Total Dissolve Solid (TDS) rejection, 76 \% for Chemical Oxyugen Demand COD rejection, and $65.3 \%$ for ammonia rejection. This value was higher than that obtained for membranes without PVA coating, namely only $47.3 \%$ for TDS, $51.1 \%$ for (COD), and $29.4 \%$ for ammonia rejection. Modifications with UV and PVA irradiation provide interrelated effects to improve membrane performance.
\end{abstract}

\section{Keywords}

refinery, polysulfone-nano ZnO membrane, wastewater treatment, UV irradiation, polyvinyl alcohol

\section{Introduction}

Oil companies use large quantities of water during the process of refining crude oil. Refineries use toxic organic compounds, such as oils and fats, which contaminate the water [1]. Therefore, oil companies must have water treatment management processes, such as optimizing usage of water, water recycling, water reuse, and maximizing water treatment system effectiveness [2]. Other research related to the purification of oil refined water waste by torma Treating refinery water with traditional methods such as adsorption and absorption cannot eliminate droplets, micro-droplets and sub-micro droplets emulsions effectively [3]. Separating the contaminants via gravity settling is time-consuming, even after adding chemicals to break the emulsion system were reported Munirasu et al. [4].
Membrane technology is a rapidly-developing method of water treatment today. Membrane technology can help in better separation, purification, and water-soluble and dispersible materials can be retained [5]. Thus, membrane technology is the best way to eliminate the micro and sub micro sized oil droplets in wastewater [6]. Kiss et al. [7] has used cross flow membrane filtration system in refinery water treatment. In a series of experiments, they demonstrated that ultrafiltration polyvinyl alcohol (PVA) membranes had superior permeate flux. Safari et al. also reported on [8] conducted a cross-flow microfiltration filtration process for oil refinery wastewater using a ceramic membrane material $\left(\mathrm{Al}_{2} \mathrm{O}_{3}\right)$ with a pore size of $50 \mathrm{~nm}$. Oily wastewater treatment goes through a urification process using 
flocculation and microfiltration [9]. However, foulant deposition on the membrane, called fouling, blocks the pores of the membrane and results in a substantial reduction of the permeable flux over the operating time function. It consequently limits the membrane's full application in wastewater treatment [10]. Many studies have investigated modifications to reduce membrane fouling and increase flux values such as modification of hydrophilicity, pore size, porosity, and surface charge [11]. Kemal et al. [12] have modified the PSF membrane with nano graphene oxide (nano-go). These modifications resulted in $97 \%$ pollutant rejection and a $219.1 \mathrm{Lm}^{-2} \mathrm{~h}^{-1}$ flux. Furthermore, Anand et al. [13] modified PSF using nano $\mathrm{ZnO}$. Such modifications increase the hydrophilicity and permeability of the PSF membrane. Membrane permeability values increased from 2.83 to 5.11 $\mathrm{Lm}^{-2} \mathrm{~h}^{-1} \mathrm{bar}^{-1}$. Chung et al. [14] also have modified the PSF membrane using nano $\mathrm{ZnO}$ and ethylene glycol as additives. The modification results showed that nano $\mathrm{ZnO}$ increases the membrane porosity as well as the permeability from $1 \mathrm{Lm}^{-2} \mathrm{~h}^{-1} \mathrm{bar}^{-1}$ to $5 \mathrm{Lm}^{-2} \mathrm{~h}^{-1} \mathrm{bar}^{-1}$. Therefore, this research is focused on nano $\mathrm{ZnO}$ incorporation into the PSF membrane matrix. However, problems often occur when the incorporation of nanoparticles in the membrane matrix causes the aggregation and formation of unselective microvoids in the membrane.

Kusworo et al. [15] has modified the polyetersulfone nano silica membrane by ultraviolet irradiation and thermal annealing. The modification results show that ultraviolet irradiation can increase the polymer chain density and the hydrophilic properties of the membrane. These modifications cause the formation of hydroxyl and carbonyl groups, to reduce the formation of microvoids. Ultraviolet irradiation is a type of membrane modification that offers simplicity, usefulness, versatility, and low cost, which makes it is widely utilized [5]. Ultraviolet irradiation can change the surface properties of the membrane without affecting the bulk properties [16]. Another method is to increase membrane hydrophilicity and reduce aggregation by adding hydrophilic material such as pva. Park et al. [17] have used PVA on the PVDF membrane by dip-coating. This modification increases the hydrophilic nature of the membrane, with flux values of $33 \mathrm{Lm}^{-2} \mathrm{~h}^{-1}$.

Refinery wastewater treatment using psf-nano $\mathrm{ZnO}$ with modification by uv irradiation and pva has not been reported yet in the literature. The focus of this research is modification of the psf nano $\mathrm{ZnO}$ composite membrane with Ultraviolet and PVA irradiation through a dip-coating technique. The modification is expected to produce a membrane with higher separation performance for refinery processing compared to that of an unmodified PSF-ZnO membrane.

\section{Materials and methods}

\subsection{Materials}

Polysulfone (PSF) (UDEL ${ }^{\circledR} \mathrm{PSU}$ ) as membrane material was obtained from Solvay Advanced Materials, USA. N-methyl-2-pyrrolidone or NMP was purchased from Merck, USA as a membrane polymer solvent. Polyvinyl alcohol (PVA) as a surface modifier additive and polyethylene-glycol $6000 \mathrm{Da}$ and $4000 \mathrm{Da}$ as a potogen agent were obtained from Merck, USA. ZnO nanoparticle as an inorganic nano-filling on the membrane Obtained from Nano Center Indonesia with specifications in Table 1. To remove water vapor absorbed, nano zno is dehydrated at $300{ }^{\circ} \mathrm{C}$ for 3 hours before use. waste oil from PT Pertamina Oil \& Gas Company Ltd. as bait. While pure water as a non-solvent from the Integrated Laboratory of Diponegoro University Semarang, Indonesia.

\subsection{Membrane preparation}

The first step in this study was the fabrication of PSF-nano $\mathrm{ZnO}$ membranes. PSF-nano $\mathrm{ZnO}$ was made by mixing nano $\mathrm{ZnO}$ with the psf polymer. Following this, the PEG additive was added to the psf-nano zno membrane matrix to improve membrane performance. The PSF-nano $\mathrm{ZnO}$ composite membrane was prepared by means of dry phase inversion. N-Methyl-2-pyrrolidone as solvent, and water for coagulation [18]. First, the PSF-nano $\mathrm{ZnO}$ solution was prepared by mixing nano $\mathrm{ZnO}(0.1 ; 0.5 ; 1 \%$ by weight) into $19 \mathrm{wt} \%$ PSF. The solution was stirred until it became homogeneous and then ultrasound was applied to the solution for 1 hour. Sulaiman et al. [19]. Have used a nano $\mathrm{ZnO}$ composite membrane PSF that has been left for 1 day to remove air

\begin{tabular}{|c|c|c|c|}
\hline \multicolumn{2}{|c|}{ Test item } & \multirow{2}{*}{$\begin{array}{c}\text { Unit } \\
-\end{array}$} & \multirow{2}{*}{$\frac{\text { Test result nano } \mathrm{ZnO}}{6-7}$} \\
\hline 1 & $\mathrm{pH}$ & & \\
\hline 2 & Structure & - & Crystalline \\
\hline 3 & Assay & $\%$ & $>99$ \\
\hline 4 & Oil Absorption & $\mathrm{g} / 100 \mathrm{~g}$ & 32 \\
\hline 5 & Density & $\mathrm{g} / \mathrm{cm}^{3}$ & 2.90 \\
\hline 6 & Size & $\mathrm{nm}$ & 341.7 \\
\hline \multirow[t]{4}{*}{7} & Color & & \\
\hline & $\mathrm{L}^{*}$ & - & 94.810 \\
\hline & $a^{*}$ & - & 1.890 \\
\hline & $\mathrm{b}^{*}$ & - & 4.110 \\
\hline
\end{tabular}


bubbles trapped in the solution due to stirring. The solution was cast on a glass plate with a membrane thickness of $0.1 \mathrm{~mm}$, and then the polymer is immersed into the coagulation site. In this study, a thin layer of the membrane was then soaked with water for 24 hours to separate the solvent trapped in the membrane matrix [19]. Membrane sheets were dried at room temperature for 24 hours [20]. The effect of using UV irradiation causes degradation of the polymer chains resulting in larger pores [21]. In addition, the effects of PEG and UV irradiation can create surface creases that extend, such as fingers, into the sub-layers, and large holes in the lower surface, as seen in Fig. 1(c). In Fig. 1(d), many white spots indicate spread of pva on the membrane sheet. Furthermore, the pores in Fig. 1(d) are less good when compared to Fig. 1(b) because the surface of the membrane is coated by PVA, resulting in cross-linking between PVA and the PSF-nano $\mathrm{ZnO}$ membrane

\subsection{Modification of the membrane}

Modification of the PSF-nano $\mathrm{ZnO}$ membrane was carried out in two steps in series. The first modification is uv irradiation on the pre-coagulated membrane. A UV lamp type $\mathrm{C}$ with wavelength of $254 \mathrm{~nm}$ was used in this work [8]. The dope solution was made with $19 \mathrm{wt} \%$ PSF, the optimal nano $\mathrm{ZnO}$ concentration, and the optimal PEG molecular weight based on membrane performance (flux and rejection) evaluation in the previous procedure. The solution was poured on the glass holder and then exposed to UV with a variable time of 1,3 , or 5 minutes. Subsequently, the glass plate was put in a coagulation bath for 1 hour, and the membrane sheet was soaked for 24 hours. The next step followed the previous method of membrane fabrication. UV-treated PSF-nano $\mathrm{ZnO}$ membrane sheet was evaluated for its performance in filtering refinery wastewater. The uv irradiated membrane that possessed the best performance was then modified using a pva coating [22]. PVA solutions were prepared at concentrations of 1,3 , and $5 \%$ by weight. PVA was dissolved in distilled water at a temperature of $90{ }^{\circ} \mathrm{C}$ with stirring for 120 minutes. After that, the PVA-coated membrane sheet was allowed to stand for 8 hours, and dried at room temperature.

\subsection{Characterization and performance of psf-nano zno membranes}

\subsubsection{PSF-nano zno membrane performance}

The membrane was made by pouring on the surface of the glass using PSF-ZnO hubcap solution which was made from mixing $19 \%$ PSF, $1 \%$ nano zno, and $5 \%$ PEG plus
NMP solvent. The solution is stirred for half a day so that the solution is stable and homogeneous. Then the solution is left to stand for 1 day to get a perfect membrane such as the loss of air bubbles that are dissolved. then pouring using dry-wet phase inversion technique. After that the membrane was immersed in the coagulation place. After that the PSF-nano $\mathrm{ZnO}$ membrane was dried in an oven at room temperature. The membrane was prepared to obtain flux and rejection products. after that the hubcap solution was poured on a glass plate, and exposed to UV. The UV lamp used was type $\mathrm{C}$ with a wave of $254 \mathrm{~nm}$ and a power of 10 watts. The duration is 2 minutes. Then the membrane film is immersed into the coagulation bath. Furthermore, PVA was added to the PES-nano $\mathrm{ZnO}$ membrane solution by dip-coating method, by dissolving $1,3.5 \mathrm{wt} \%$ PVA into an air distillate at $90{ }^{\circ} \mathrm{C}$. The membrane was prepared in a performance test based on the results of flux and rejection. The permeate flux, rejection and flux reduction ration were evaluated using Eqs. (1), (2), and (3), respectively.

$$
J_{w}=\frac{V}{A \times t},
$$

where $J_{w}$ is the flux $\left(\mathrm{Lm}^{-2} \mathrm{~h}^{-1}\right), V$ is the permeate volume (L), $A$ is the active membrane area $\left(12.57 \mathrm{~cm}^{2}\right)$, and $t$ is the operating time interval (hour).

$R=\left(1-\frac{C_{p}}{C_{f}}\right) \times 100 \%$,

where $C_{p}(\mathrm{mg} / \mathrm{l})$ and $C_{f}(\mathrm{mg} / \mathrm{l})$ are concentrations in permeate and feed, respectively. Rejection is calculated based on the reduction of contaminants in the permeate which then is evaluated. In this study, the studied wastewater parameter Total Dissolve Solid (TDS) is analyzed using a TDS KIT (HM original), and ammonia is analyzed using a UV spectrophotometer (Shimadzu Bio spec-mini UV-Vis Spectrophotometer).

$M \%=\left(\frac{J_{0}-J_{1}}{J_{0}}\right) \times 100 \%$,

where $J_{0}\left(\mathrm{Lm}^{-2} \mathrm{~h}^{-1}\right)$ is the pure water flux, and $J_{1}\left(\mathrm{Lm}^{-2} \mathrm{~h}^{-1}\right)$ is the flux of wastewater during filtration at 150 minutes [23].

\subsection{Fabrication of membrane psf-nano zno}

Surface morphology and cross-sectional the structure/ shape of the PSF-nano zno membrane was analyzed by SEM (JEOL series JSM6510LA, Japan). The membrane sample was placed in liquid nitrogen and divided with a clamp. The membrane was placed in a gold-plated 
sample case, with tape added. Furthermore, the membrane morphology test was carried out with a magnification of 1000 times and an enlargement of 5000 times with a voltage of $20 \mathrm{kV}$. for functional group membranes using FTIR. The wavelength FTIR spectra were used to observe the PSF-nano $\mathrm{ZnO}$ membrane in the wavenumber range $4000-400 \mathrm{~cm}^{-1}$. Furthermore, the analysis of membrane surface hydrophilicity was determined by the water contact angle of the membrane and was calculated using the sessile droplet method at constant temperature (room temperature). When the water droplets stabilized after 30 seconds, observations were made during a 4-minute observation duration. As reported by [24] membrane porosity using a gravimetric method. The membrane was immersed in de-ionized water for 1 day, then cleaned and weighed and dried at $60{ }^{\circ} \mathrm{C}$ and then weighed again to get the dry weight of the membrane [25]. To get membrane porosity then use Eq. (4).

$$
\varepsilon=\frac{w t_{0}-w t_{i}}{\rho_{\text {water }} \times A \times l},
$$

where $\varepsilon$ is the porosity of the membrane, and $w t_{i}$ and $w t_{0}$ are the weights of the wet and dry membranes (g), respectively. $\rho_{\text {water }}$ is the density of pure water at $25{ }^{\circ} \mathrm{C}$ $\left(0.997 \mathrm{~g} \mathrm{~cm}^{-3}\right), A$ is the active area of the membrane $\left(\mathrm{cm}^{2}\right)$, and $l$ is the membrane thickness $(\mathrm{cm})$.

\section{Results and discussion}

\subsection{Effect of PVA modification and UV on membrane morphological structure}

SEM analysis is used for the study of membrane morphology, surface condition, and sublayer membrane relations. SEM test results can determine the effect of PVA coating on the matrix membrane PSF-nano $\mathrm{ZnO}$ composites. The results of the membrane characterization are shown in Fig. 1.

Fig. 1(a) shows the surface of the membrane PSF-nano $\mathrm{ZnO}$ composite with modification. The surface looks cleaner, and the pores are not clearly visible compared to Fig. 1(b). Fig. 1(b) shows a membrane surface that has been changed by adding PEG 6000 Da additives and 1 minute of UV irradiation. PEG is used as a pore-forming agent in polymers, which causes more pores. High molecular weight PEG formed voids with PEG 4000 on the membrane matrix [26], as did the Ultraviolet irradiation on the membrane matrix. UV irradiation on the membrane matrix is used in Fig. 1(a) because it causes degradation in the polymer chain. Degradation forms radicals that function for polymerization [27]. At longer UV irradiation times, the influence of polymer chain degradation results in increasingly larger pores [28]. The effect of PEG and uv irradiation also creates surface hollows which extend, fingerlike, into the sublayers, and large holes in the lower surface, as seen in Fig. 1(c). In Fig. 1(d), many white spots show PVA spread on the membrane surface.
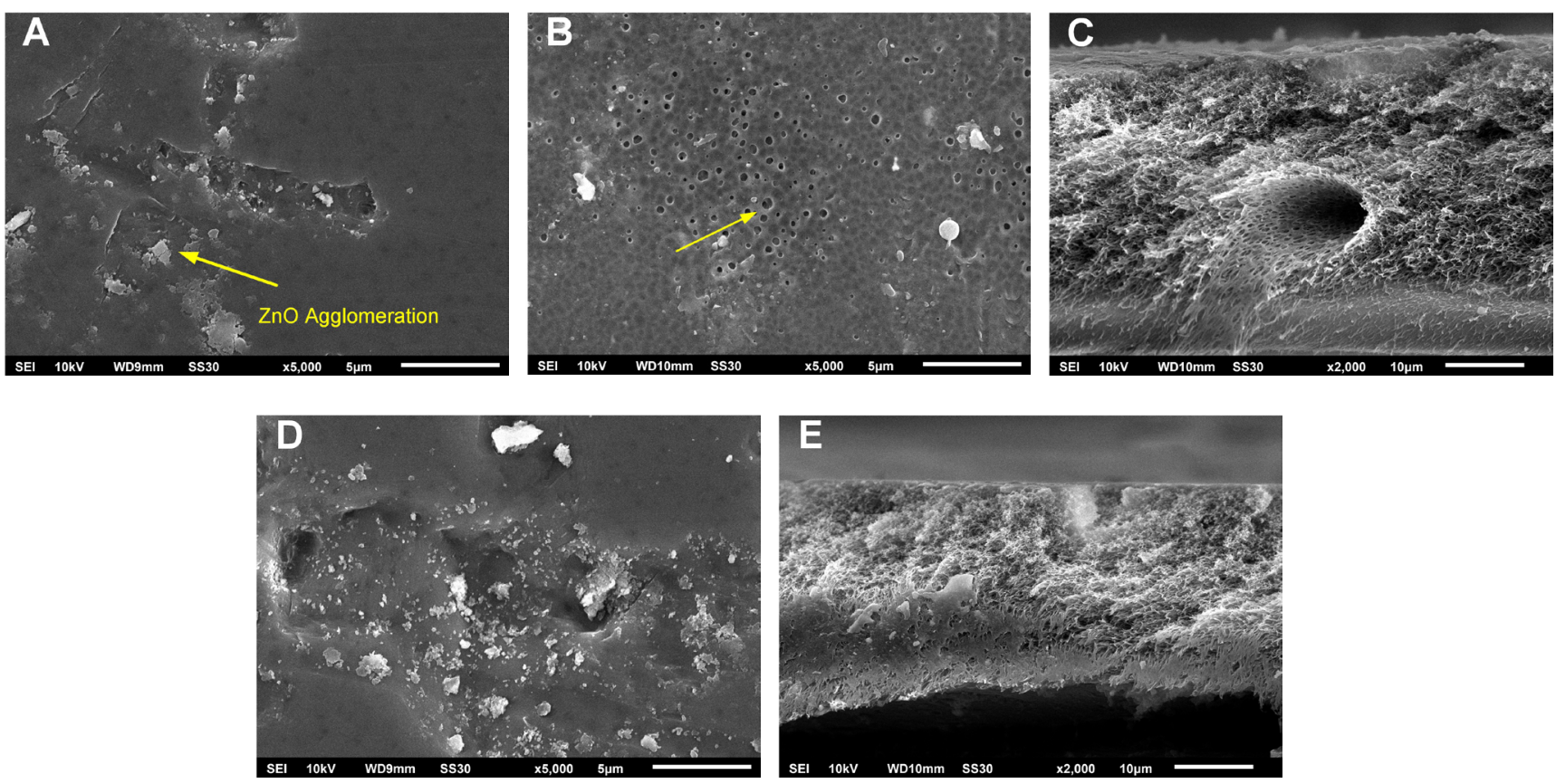

Fig. 1 Morphology of the PSF-nano ZnO membrane; (a) The surface of the membrane PSF-nano ZnO composites; (b) surface of the PSF-nano ZnO membrane treated with 6000 Da PEG and 1 min UV (before filtration); (c) cross section of the PSF-nano ZnO membrane treated with 6000 Da PEG and 1 min UV; (d) surface of the PSF-nano ZnO membrane with $3 \mathrm{wt} \%$ PVA addition (before filtration); and (e) cross section of the PSF-nano ZnO membrane 
Furthermore, the pores in Fig. 1(d) are less clear than in Fig. 1(b) because the membrane surface is coated by PVA, resulting in cross-linking between PVA and the PSF-nano composite $\mathrm{ZnO}$ membrane [29]. Fig. 1(e) is a cross-section image of the PSF-nano $\mathrm{ZnO}$ membrane coated with PVA. The cross-section structure is neater and tighter compared to Fig. 1(c). Fig. 1(e) shows the presence of PVA in the membrane, improving the membrane structure and forming a thin layer so that the membrane surface is denser than the membrane without PVA. Then, the PSF-nano $\mathrm{ZnO}$ membrane after filtration was characterized by SEM. The SEM results explain a condition that occurs between refinery impurities and membrane surfaces. The results of the characterization after filtration are presented in Fig. 2.

Fig. 2(a) shows the PSF-nano $\mathrm{ZnO}$ membrane with 6000 Da PEG and 1 minute UV treatment after filtration. Cake foulant can be seen on the membrane surface due to contaminants in wastewater accumulating on the membrane surface. Fig. 2(b) is a SEM image of a psf-nano zno

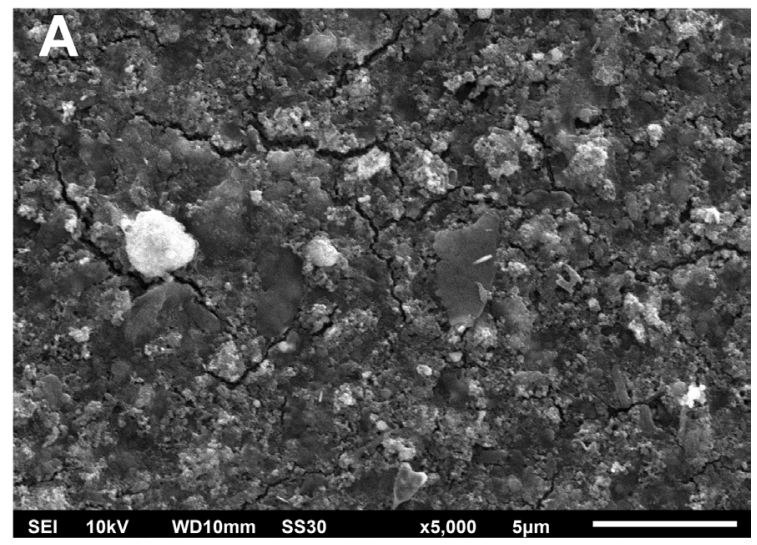

(a)

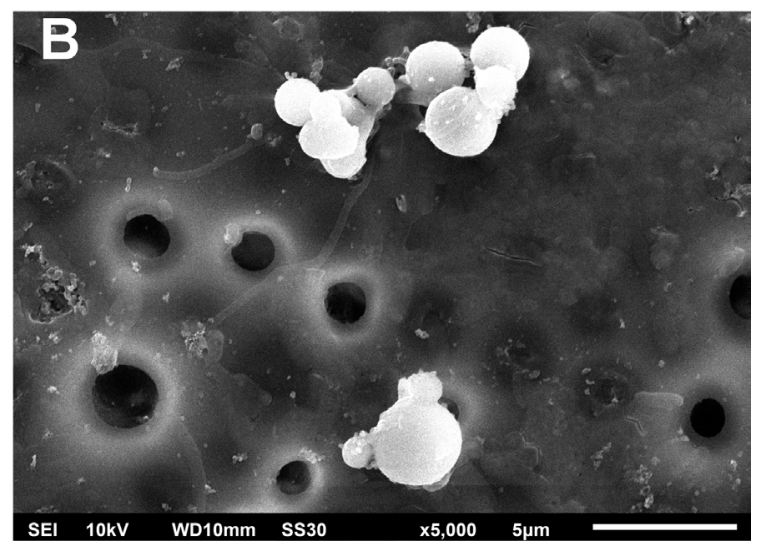

(b)

Fig. 2 Morphology of the PSF-nano ZnO membrane; (a) The surface of the PSF-nano ZnO membrane treated with 6000 Da PEG and 1 min UV after filtration; (b) The surface of the PSF-nano $\mathrm{ZnO}$ membrane with PVA coating after filtration membrane surface that has been coated with PVA, which shows less accumulation of pollutants on the membrane surface. In the picture the membrane forms a layer of cake, as in Fig. 2(a); only the number of different cakes differs between processes. Fig. 2(b) shows the slight accumulation of pollutants on the surface which does not form a cake layer as in Fig. 2(a).

\subsection{Effect of PVA modification on contact angle values}

The stability and selectivity of the membranes often depend on the properties of the membrane used in the filtration process. The membrane properties can be seen based on the membrane contact angle values; the PSF-nano $\mathrm{ZnO}$ membrane contact angle values are shown in Table 2.

Table 2 shows that the contact angle value of the PSFnano $\mathrm{ZnO}$ membrane reaches $72.33^{\circ}$ when $0.1 \mathrm{wt} \%$ of nano $\mathrm{ZnO}$ was added. This result explains nano $\mathrm{ZnO}$ is added to the matrix of the membrane that has been mixed so smoother membrane surface with nano $\mathrm{ZnO} 0.5 \mathrm{wt} \%$. This phenomenon is caused by the low water solubility of PEG $4000 \mathrm{Da}$ and water solubility, so that the membrane's surface is rougher than the membrane without PEG [30]. A rough membrane surface and hydrophilic PEG properties can increase the hydrophilicity of the PSF-nano $\mathrm{ZnO}$ membrane. Furthermore, prolonged exposure of the PSF-nano $\mathrm{ZnO}$ membrane matrix to UV light causes the contact angle to decrease down to $55.17 \%$. This result shows that more exposure to UV irradiation for the PSF-nano $\mathrm{ZnO}$ membrane causes matrix bonds to degrade and form radicals, as described by Sarihan et al. [31]. These values indicate that the PSF-nano $\mathrm{ZnO}$ membrane modified by UV irradiation can increase membrane hydrophilicity.

Table 2 PSF-nano $\mathrm{ZnO}$ contact angle membrane values with various modifications

\begin{tabular}{ccc}
\hline $\begin{array}{c}\text { Membrane } \\
\text { name }\end{array}$ & Membrane composition & $\begin{array}{c}\text { Contact } \\
\text { angle }\left(^{\circ}\right)\end{array}$ \\
\hline PS1 & PSF 19\% & $70.75 \pm 0.1$ \\
PS2 & $19 \mathrm{PSF}+0.1 \mathrm{ZnO}$ & $72.33 \pm 0.01$ \\
PS3 & $19 \mathrm{PSF}+0.5 \mathrm{ZnO}$ & $71.83 \pm 0.02$ \\
PS4 & $19 \mathrm{PSF}+1 \mathrm{ZnO}$ & $72.00 \pm 0.01$ \\
PS5 & $19 \mathrm{PSF}+1 \mathrm{ZnO}+6000 \mathrm{PEG}$ & $70.00 \pm 0.01$ \\
PS6 & $19 \mathrm{PSF}+1 \mathrm{ZnO}+4000 \mathrm{PEG}$ & $73.08 \pm 0.01$ \\
PS7 & $19 \mathrm{PSF}+1 \mathrm{ZnO}+6000 \mathrm{PEG}+1 \mathrm{UV}$ & $66.33 \pm 0.02$ \\
PS8 & $19 \mathrm{PSF}+1 \mathrm{ZnO}+6000 \mathrm{PEG}+3 \mathrm{UV}$ & $71.42 \pm 0.01$ \\
PS9 & $19 \mathrm{PSF}+1 \mathrm{ZnO}+6000 \mathrm{PEG}+5 \mathrm{UV}$ & $55.17 \pm 0$ \\
PS10 & 19PSF $+1 \mathrm{ZnO}+6000 \mathrm{PEG}+1 \mathrm{UV}+1 \mathrm{PVA}$ & $36.42 \pm 0.01$ \\
PS11 & 19PSF $+1 \mathrm{ZnO}+6000 \mathrm{PEG}+1 \mathrm{UV}+2 \mathrm{PVA}$ & $39.92 \pm 0.01$ \\
PS12 & 19PSF $+1 \mathrm{ZnO}+6000 \mathrm{PEG}+1 \mathrm{UV}+3 \mathrm{PVA}$ & $41.50 \pm 0$ \\
\hline
\end{tabular}


Furthermore, the response in contact angle to the presence of a PVA coating on the PSF-nano $\mathrm{ZnO}$ membrane's top layer as the final modification is similar to the response to UV irradiation. The contact angle value of the membrane reaches $36.42 \%$, lower than that of the uncoated membrane. A similar result was also reported by Zangeneh et al. [32], showing that low PVA concentrations can penetrate into the matrix, making the substrate even bigger [33]. With a higher concentration, the PVA can form a thin layer on the surface which results in decreased membrane hydrophilicity.

\subsection{FTIR characterization of the modified membrane: UV irradiation and PVA coating}

FTIR is used to measure the membrane spectrum so that the functional groups on the membrane can be determined. The FTIR spectra of the prepared membranes are shown in Fig. 3.

Fig. 3 shows the spectra of the PSF-nano $\mathrm{ZnO}$ membrane with multiple modifications. Intense absorption occurs in one of the membrane samples at wavenumbers of 1290 and $1325 \mathrm{~cm}^{-1}$, representing symmetrical stretch vibrations $\mathrm{O}=\mathrm{S}=\mathrm{O}$ coming from pure PSF as the main chain in the membrane matrix. The two peaks at wavenumbers of 1365 and $1488 \mathrm{~cm}^{-1}$ correspond to the symmetrical deformation vibrations and the asymmetrical deformation vibrations respectively. The rotation of the $\mathrm{C}=\mathrm{C}$ conjugate mechanism of the benzene ring leads to the observed absorption rate at $1585 \mathrm{~cm}^{-1}$. Meanwhile, the wavenumber of $3000 \mathrm{~cm}^{-1}$ shows asymmetrical stretching vibration of $-\mathrm{CH}$ [34]. Furthermore, the $1756 \mathrm{~cm}^{-1}$ region's wavelength changed after adding $1 \mathrm{wt} \%$ nano. The absorption shows

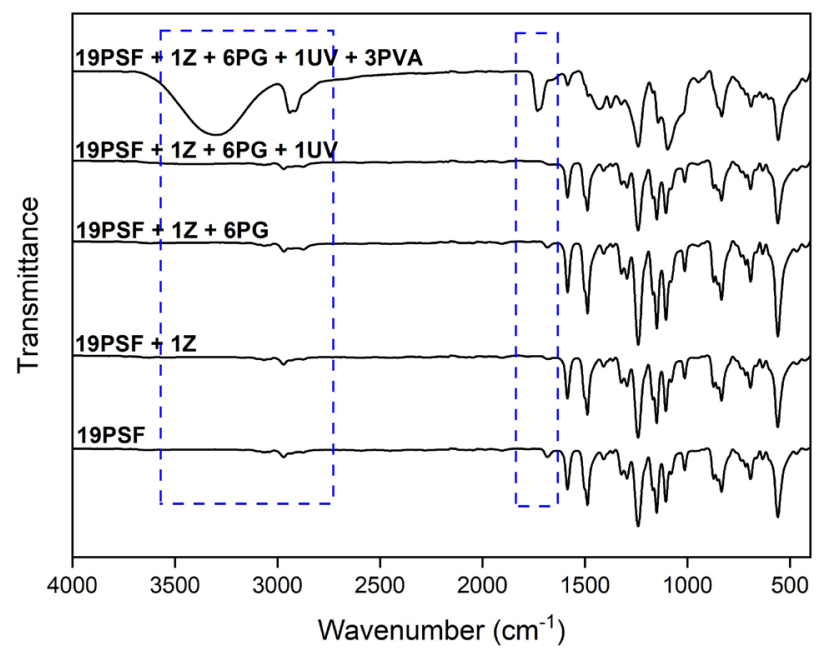

Fig. 3 The FTIR spectrum of the PSF-nano $\mathrm{ZnO}$ membrane with various modifications strong water adsorption due to the presence of a hydroxyl group in the PVA chain [35]. Nevertheless, the modification of the psf-nano zno membrane did not change the main membrane matrix chain. This phenomenon shows that the membrane produced is stable and that this modification method does not cause backbone damage to the membrane.

\subsection{The effect of PVA modification on the porosity of the PSF-nano ZnO membrane}

Membrane porosity is defined as the ratio of the membrane pore volume to the total volume. Porosity can affect the efficacy of membrane performance (flux and rejection). The porosity values of the PSF-nano $\mathrm{ZnO}$ membrane with different modifications are shown in Fig. 4.

Fig. 4 shows that addition of nano $\mathrm{ZnO}$ to the psf membrane increased its porosity to $64 \%$ at nano $\mathrm{ZnO} 1 \mathrm{wt} \%$. The increase in porosity due to the presence of nano $\mathrm{ZnO}$ resulted in the formation of microvoids between the PSFnano $\mathrm{ZnO}$ membrane matrices [36]. However, an increase in nano $\mathrm{ZnO}$ concentration resulted in a decrease in porosity of up to $62 \%$ at $1 \mathrm{wt} \%$ nano $\mathrm{ZnO}$. As reported by Kuvarega et al. [37], this phenomenon suggests that the high concentrations of nano $\mathrm{ZnO}$ cause the distance between pores to be smaller compared to low nano $\mathrm{ZnO}$ concentrations, meaning that membrane density increases. The distance between the pores occurs because nano $\mathrm{ZnO}$ is scattered around the matrix of the PSF membrane. PEG modification and UV irradiation have the same effect on the PSF-nano $\mathrm{ZnO}$ membrane matrix by increasing the porosity value. The porosity value reaches $86 \%$ after the addition of PEG, and porosity in membranes exposed to UV light is higher than in the membrane without UV irradiation exposure. These results are consistent with the SEM report in Fig. 1, where the pores on the treated membrane surface are visible. Before the coagulation process,

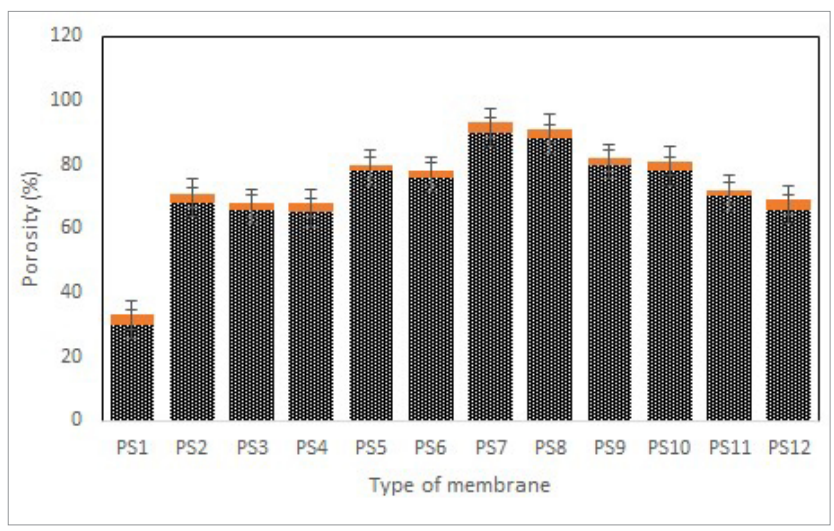

Fig. 4 Porosity values of various PSF-nano $\mathrm{ZnO}$ membranes 
UV irradiation allows the demixing process to be delayed, which causes the formation of voids. The molecular weight of PEG causes the membrane matrix to allow water to pass through the membrane efficiently and leaves pore traces on the membrane. Large numbers of pores improve the performance (flux and rejection) of the membrane. The last modification, PVA, when attached to the surface, can decrease the porosity value to $65 \%$. This phenomenon occurs because solutions with low concentrations of PVA ( $1 \%, 2 \%$ and $3 \%$ ) can enter the membrane matrix to reduce the volume of the pore. High levels of PVA can form a coating on the membrane surface that affects the rejection of the PSF-nano $\mathrm{ZnO}$ membrane [38].

\subsection{The effect of PVA modification on the performance of the PSF-nano ZnO membrane}

\subsubsection{PSF-nano ZnO membrane performance}

The flux characteristic of membrane performance can be seen from the results of permeability and selectivity. Permeability (flux) is determined by the amount of permeate volume that passes through the membrane per unit area per time. The amount of permeate produced depends on the porosity and hydrophilicity of the membrane. The selectivity (rejection) is defined by the ability of the membrane to retain pollutant. The flux and rejection values of the PSF-nano $\mathrm{ZnO}$ membrane can be seen in Fig. 5.

The $\mathrm{ZnO}$-embedded membranes have higher flux values than that of the membrane without nano $\mathrm{ZnO}$. The flux value was $1.85 \mathrm{Lm}^{-2} \mathrm{~h}^{-1}$, higher than that for the pristine PSF membrane which reaches only $1.6 \mathrm{Lm}^{-2} \mathrm{~h}^{-1}$. This effect is correlated with increasing porosity in the presence of nano $\mathrm{ZnO}$. The nano $\mathrm{ZnO}$ has a higher reacting surface area and is well dispersed in the structure [39]. The flux value decreases with an increasing concentration of nano $\mathrm{ZnO}$ according to the decreasing porosity value. PEG molecular weight (PDI) affects the flux value. The higher molecular weight of PEG (PEG $6000 \mathrm{Da}$ ) causes a higher flux value of PEG $6000 \mathrm{Da}$. PSF-nano $\mathrm{ZnO}$ rejection value is higher, especially at $1 \mathrm{wt} \%$ nano ZnO PEG 6000 Da compared to PSF membranes without nano $\mathrm{ZnO}$. This phenomenon is due to the decreased porosity value after the addition of $1 \mathrm{wt} \%$ nano $\mathrm{ZnO}$ so that the density increases. However, the presence of PEG decreased the rejection value in the membrane to $48.4 \%$ for TDS, $52.4 \%$ for Chemical Oxygen Demand (COD) and $29 \%$ for ammonia when PEG 6000 was added during membrane preparation. This phenomenon is caused by an increase in porosity, pore size, and the hydrophilic nature of the membrane due to the addition of

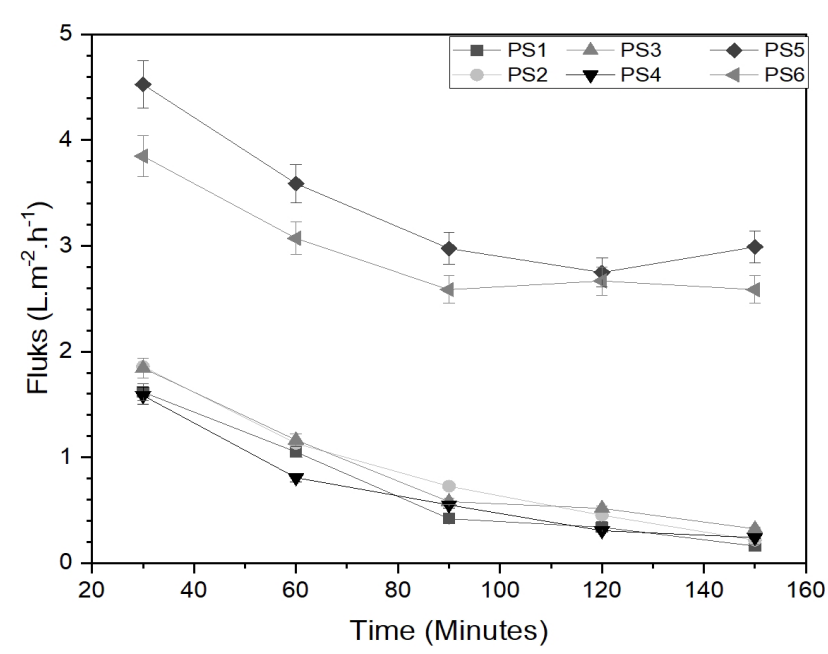

(a)

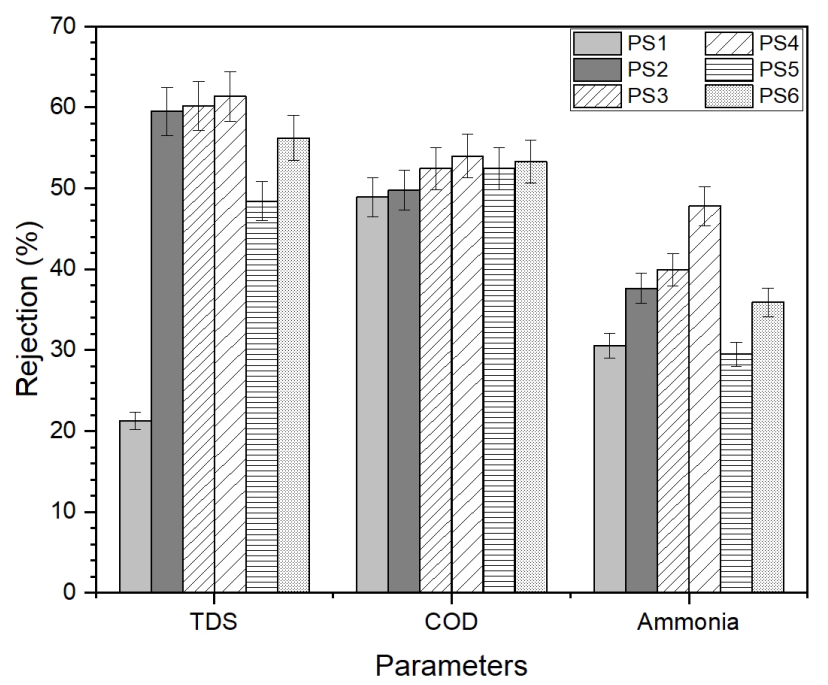

(b)

Fig. 5 (a) Flux values of PSF-nano $\mathrm{ZnO}$ (modified) membranes;

(b) Rejection values of PSF-nano $\mathrm{ZnO}$ modified membranes

PEG, so that contaminants may not be retained. Based on the research results, the concentration of nano $\mathrm{ZnO}$ membrane with the best performance was $1 \%$, while the best molecular weight of polyethylene glycol (PEG) in this study was 6000 Da which its use increased the flux value significantly compared to its decrease in the rejection value [40].

\subsubsection{Performance of the PSF-nano ZnO membrane with PVA modification}

The modification of the PSF-nano $\mathrm{ZnO}$ membrane is intended to improve the membrane flux and rejection. Based on the results of membrane characterization, the modifications made to the membrane affect the porosity level and hydrophilicity of the PSF-nano ZnO membrane. The performance of the UV irradiated and PVA-coated PSF-nano $\mathrm{ZnO}$ membranes are shown in Fig. 6. Fig. 6 shows that 
UV-irradiated membranes have significant enhancements in flux values. The flux value of UV irradiated PSF-nano $\mathrm{ZnO}$ membrane with PEG 6000 is $5.7 \mathrm{Lm}^{-2} \mathrm{~h}^{-1}$, higher than that of an unirradiated membrane with the same $\mathrm{ZnO}$ and PEG 6000 treatment, which only reaches $4.5 \mathrm{Lm}^{-2} \mathrm{~h}^{-1}$. This effect is related to the porosity value that increases with the presence of UV radiation. Nevertheless, PVA modification has a different impact on membrane separation performance: PVA lowers the flux value to $3.3 \mathrm{Lm}^{-2} \mathrm{~h}^{-1}$ with the addition of $1 \mathrm{wt} \%$ of PVA. The flux value decreases to $2.9 \mathrm{Lm}^{-2} \mathrm{~h}^{-1}$ with increasing PVA concentration of $3 \mathrm{wt} \%$ PVA. The flux of a PVA coated membrane is lower than that of an uncoated membrane. However, the effect of PVA on the membrane flux value is more stable from the beginning of the filtration to the end of the filtration compared to that of uncoated membranes. Such results indicate that the presence of PVA decreases the fouling of the membrane, considering the results of the SEM characterization of PSFnano $\mathrm{ZnO}$ membranes after filtration in Fig. 6.

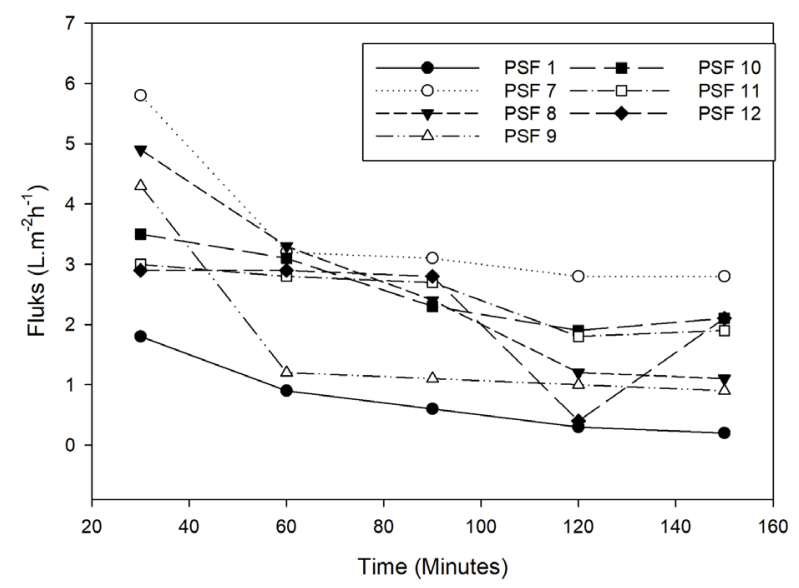

(a)

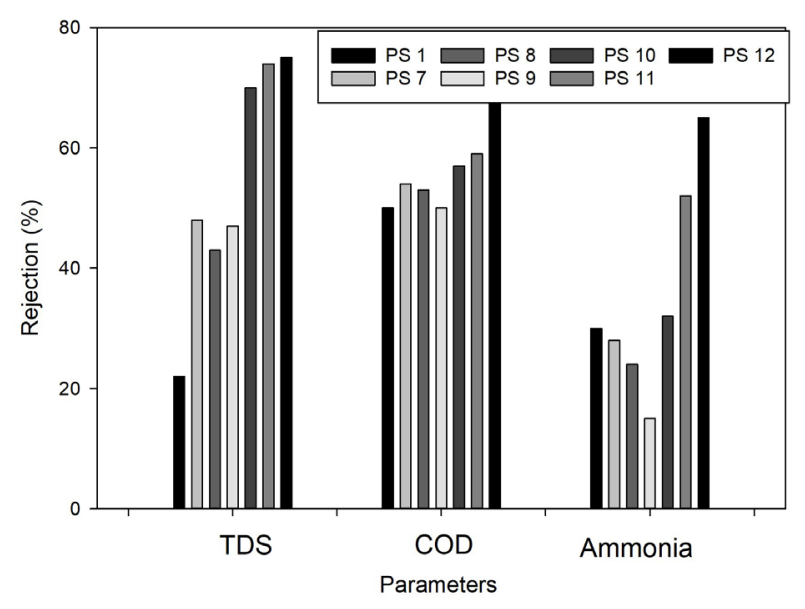

(b)

Fig. 6 (a) Flux value of PSF-nano $\mathrm{ZnO}$ (modified) membranes;

(b) Rejection value of PSF-nano $\mathrm{ZnO}$ modified membranes
The rejection value decreases with increased UV irradiation time. Such results are due to the more extended UV irradiation contributing to the degradation of the polymer membrane chain. Degradation of the membrane matrix causes an increase in the porosity of the membrane, causing waste pollutants to pass through the membrane matrix. PSF-nano $\mathrm{ZnO}$ membrane rejection after UV irradiation decreased to $46.6 \%$ rejection of TDS, $48.8 \%$ rejection of $\mathrm{COD}$, and $15 \%$ rejection of ammonia, lower than for the membrane without UV irradiation. The rejection value of the PVA-coated PSF-nano $\mathrm{ZnO}$ membrane is enhanced significantly compared to those of unmodified PSF-nano $\mathrm{ZnO}$ membrane and UV irradiated PSF-nano $\mathrm{ZnO}$ membrane. Rejection values were $77.2 \%$ higher for TDS, $76 \%$ for COD rejection and $65.3 \%$ for ammonia rejection. This is because PVA increases the hydrophilicity of the membrane corresponding to the contact angle results. The hydrophilicity of the membrane is essential during the refinery water filtration process because the hydrophobic pollutants in the refinery water are retained and do not pass through the hydrophilic membrane. In particular, the hydrophilic nature is essential to reduce TDS and COD, as stated by Meng et al. [41]. The best UV irradiation time for this analysis is 1 minute, because the flux increases significantly compared to the decrease in the rejection value. The significant PVA concentration in this experiment was $3 \%$ because at this concentration the rejection value was higher than the decrease in flux value.

\subsection{The effect of PVA modification on anti-fouling properties of PSF-nano ZnO membranes}

The anti-fouling analysis results can be explained based on the results of SEM of the PSF-nano $\mathrm{ZnO}$ membrane before and after filtration in Figs. 1 and 2. The FTIR characterizations of the PSF-nano $\mathrm{ZnO}$ membrane before and after filtration are shown in Fig. 7. Fig. 7 shows the FTIR spectra of the PSF-nano $\mathrm{ZnO}$ membrane with the addition of uv irradiation and PVA (before and after filtration). Based on these images, after filtration, changes occur in the FTIR spectrum. The spectrum changed in the range of $3300 \mathrm{~cm}^{-1}$, which represents the stretching of $\mathrm{O}-\mathrm{H}$ after 2.5 hours of titration. These changes indicate that there is an interaction between the surface of the membrane and the contaminants in the waste refinery. Nonetheless, there was no change in wavenumbers of 1290 and $1325 \mathrm{~cm}^{-1}$, which represented symmetrical stretch vibrations $\mathrm{O}=\mathrm{S}=\mathrm{O}$ from pure PSF as the main chain. 


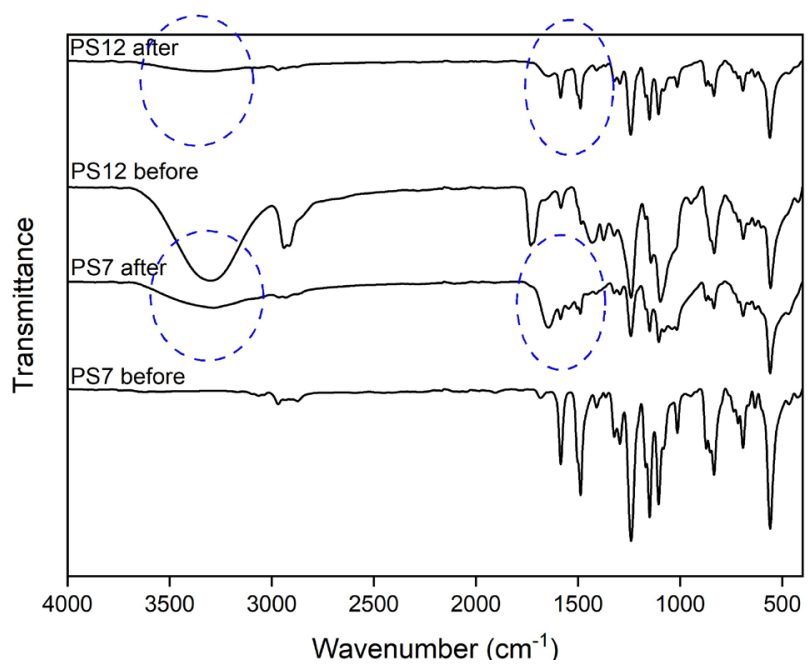

Fig. 7 The FTIR spectrum PSF-nano ZnO membrane modified (before and after filtration)

\subsection{Effect of PVA modification on PSF-nano $\mathrm{ZnO}$ membrane stability}

The stability of the membrane against the presence of fouling on the surface can be analyzed based on the flux reduction ratio. The flux reduction ratio is calculated based on the percentage of the membrane's decrease ratio. These results are confirmed by the ratio of membrane flux decrease as shown in Fig. 8.

Fig. 8 indicates that the application of UV irradiation and PVA has a significant influence on the value of the flux. Membrane flux values without modification decreased to $39 \%$ at 0.5 hours of filtration. Flux values are unstable and will continue to decline for up to 2.5 hours of filtration. However, UV irradiation of the membrane increases the flux value and its stability during the filtration process for $2.5 \mathrm{~h}$. The reduction ratio of the PSF-nano $\mathrm{ZnO}$ membrane flux with uv irradiation is lower at $1.97 \%$ than that of a similar membrane without uv irradiation. This effect shows that the fouling of membranes treated with UV irradiation occurs more slowly [42]. The last modification of the PSF-nano $\mathrm{ZnO}$ membrane was the PVA coating. This modification causes the flux reduction ratio to be only $1 \%$ lower than the PSF-nano $\mathrm{ZnO}$ membrane with uv irradiation. These results suggest that the presence of PVA increases the

\section{References}

[1] Arefi-Oskoui, S., Khataee, A., Safarpour, M., Vatanpour, V. "Modifi cation of polyethersulfone ultrafiltration membrane using ultrasonic-assisted functionalized MoS2 for treatment of oil refi nery wastewater", Separation and Purification Technology, 238, Article number: 116495, 2020.

https://doi.org/10.1016/j.seppur.2019.116495

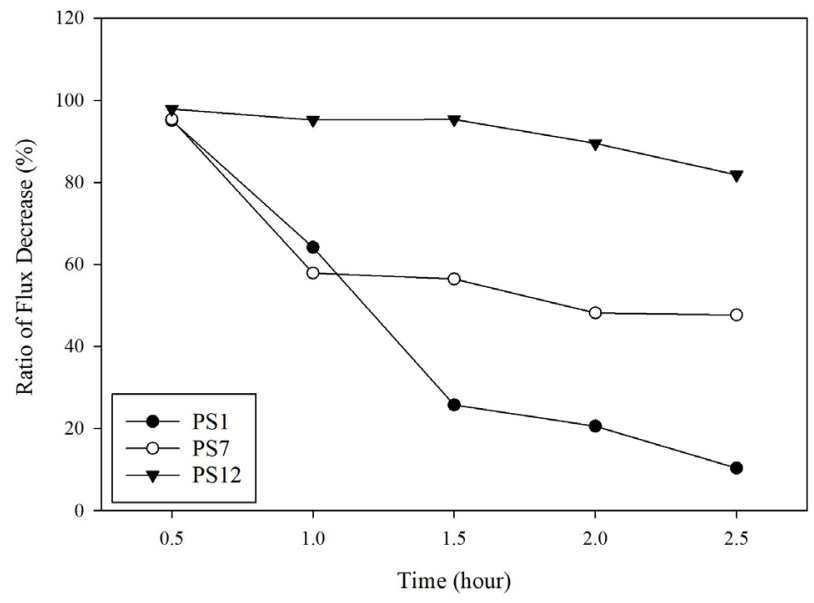

Fig. 8 Decrease ratio of PSF-nano $\mathrm{ZnO}$ membrane flux values

antifouling capability of the membrane. The flux reduction ratio in the graph is more stable from the beginning of filtration to the end of filtration. This effect implies that there is no accumulation on the surface of the membrane.

\section{Conclusion}

Modifications of the PSF-nano $\mathrm{ZnO}$ membrane by UV irradiation and PVA coating allow the membrane to be affected. UV irradiation increases the membrane flux but reduces the rejection value, while PVA decreases the flux value and increases the rejection value.

The refinery water treatment with the PSF-nano $\mathrm{ZnO}$ membrane is $2.9 \mathrm{~L} \mathrm{~m}^{-2} \mathrm{~h}^{-1}$ at 6 bar for 2.5 hours, with values for rejection of $77.2 \%$ for TDS rejection, $76 \%$ for COD rejection, and $65.3 \%$ for ammonia rejection. The results suggest that a membrane composition with $19 \mathrm{wt} \% \mathrm{PSF}$, $1 \%$ nano $\mathrm{ZnO}, 6000 \mathrm{Da}$ PEG, 1 minute UV and $3 \mathrm{wt} \%$ PVA performs the best out of the investigated variations for refinery water filtration.

\section{Acknowledgement}

We gratefully acknowledge the facility support from the Waste management laboratory of Chemical Engineering Department and Excellent Applied Research Higher Education grant under Ministry of Research, Technology and Higher Education 2019.

[2] Adham, S., Hussain, A., Minier-Matar, J., Janson, A., Sharma, R. "Membrane applications and opportunities for water management in the oil \& gas industry", Desalination, 440, pp. 2-17, 2018. https://doi.org/10.1016/j.desal.2018.01.030

[3] Torma, C. Z., Cséfalvay, E. "Nanofiltration: A Final Step in Industrial Process Water Treatment", Periodica Polytechnica Chemical Engineering, 62(1), pp. 68-75, 2018. https://doi.org/10.3311/PPch.10640 
[4] Munirasu, S., Haija, M. A., Banat, F. "Use of membrane technology for oil field and refinery produced water treatment - A review", Process Safety and Environmental Protection, 100, pp. 183-202, 2016.

https://doi.org/10.1016/j.psep.2016.01.010

[5] Aryanti, N., Kusworo, T. D., Oktiawan, W., Wardhani, D. H. "Performance of Ultrafiltration-Ozone Combined System for Produced Water Treatment", Periodica Polytechnica Chemical Engineering, 63(3), pp. 438-447, 2019.

https://doi.org/10.3311/PPch.13491

[6] Moeinzadeh, R., Jadval Ghadam, A. G., Lau, W. J., Emadzadeh, D. "Synthesis of nanocomposite membrane incorporated with amino-functionalized nanocrystalline cellulose for refinery wastewater treatment", Carbohydrate Polymers, 225, Article number: 115212, 2019.

https://doi.org/10.1016/j.carbpol.2019.115212

[7] Kiss, Z. L., Talpas, L., Seres, Z., Beszédes, S., Hodúr, C., László, Z. "Treatment of model oily waste water by microfiltration", Periodica Polytechnica Chemical Engnineering, 57(1-2), pp. 21-24, 2013. https://doi.org/10.3311/ppch.2166

[8] Safari, N. H. M., Hassan, A. R., Che Wan Takwa, C. W. I., Rozali, S. "Deduction of Surfactants Effect on Performance, Morphology, Thermal and Molecular Properties of Polymeric Polyvinylidene Fluoride (PVDF) Based Ultrafiltration Membrane", Periodica Polytechnica Chemical Engineering, 63(1), pp. 27-35, 2019.

https://doi.org/10.3311/PPch.12423

[9] Yuliwati, E., Ismail, A. F., Matsuura, T., Kassim, M. A., Abdullah, M. S. "Effect of modified PVDF hollow fiber submerged ultrafiltration membrane for refinery wastewater treatment", Desalination, 283, pp. 214-220, 2011.

https://doi.org/10.1016/j.desal.2011.03.049

[10] Padaki, M., Emadzadeh, D., Masturra, T., Ismail, A. F. "Antifouling properties of novel PSf and TNT composite membrane and study of effect of the flow direction on membrane washing", Desalination, 362, pp. 141-150, 2015.

https://doi.org/10.1016/j.desal.2015.01.012

[11] Lerin, L. A., Loss, R. A., Remonatto, D., Zenevicz, M. C., Balen, M., Netto, V. O., Ninow, J. L., Trentin, C. M., Oliveira, J. V., Oliveira, D. "A review on lipase-catalyzed reactions in ultrasound-assisted systems, Bioprocess and Biosystems Engineering, 37(12), pp. 2381-2394, 2014.

https://doi.org/10.1007/s00449-014-1222-5

[12] Bayrak, S., Ustaoğlu, G., Demiralp, K. Ö., Kurşun Çakmak, E. Ş. "Evaluation of the Characteristics and Association Between Schneiderian Membrane Thickness and Nasal Septum Deviation", The Journal of Craniofacial Surgery, 29(3) pp. 683-687, 2018. https://doi.org/10.1097/SCS.0000000000004254

[13] Anand, A., Unnikrishnan, B.,Mao, J-Y., Lin, H-J., Huang, C. C. "Graphene-based nanofiltration membranes for improving salt rejection, water flux and antifouling-A review," Desalination, 429, pp. 119-133, 2018.

https://doi.org/10.1016/j.desal.2017.12.012
[14] Chung, X.T., Ba-Abbad, M. M., Mohammad, A. W., Benamor, A. "Functionalization of zinc oxide (zno) nanoparticles and its effects on polysulfone-zno membranes", Desalination and Water Treatment, 57(17), pp. 7801-7811, 2016.

https://doi.org/10.1080/19443994.2015.1067168

[15] Kusworo, T. D., Ismail, A. F., Aryanti, N., Widayat, W., Qudratun, Q., Utomo, D. P. "Enhanced Anti-Fouling Behavior And Performances Of Nano Hybrid Pes-Sio2 And Pes-zno Membranes For Produced Water Treatment", Jurnal Teknologi, 79(6), pp. 129-40, 2017. https://doi.org/10.11113/jt.v79.10692

[16] Garcia-Ivars, J., Iborra-Clar, M.-I., Alcaina-Miranda, M. I., Mendoza-Roca, J. A., Pastor-Alcañiz, L. "Surface photomodification of flat-sheet PES membranes with improved antifouling properties by varying UV irradiation time and additive solution $\mathrm{pH}^{\prime}$, Chemical Engineering Journal, 283, pp. 231-242, 2016. https://doi.org/10.1016/j.cej.2015.07.078

[17] Park, M. J., Gonzales, R. R., Abdel-Wahab, A., Phuntsho, S., Shon, H. K. "Hydrophilic polyvinyl alcohol coating on hydrophobic electrospun nanofiber membrane for high performance thin film composite forward osmosis membrane", Desalination, 426, pp. 50-59, 2018.

https://doi.org/10.1016/j.desal.2017.10.042

[18] Kusworo, T. D., Widayat, W., Utomo, D. P. "Fabrication and Characterization of Nano Hybrid Cellulose Acetate-nanoTiO2/ crosslinked Polyvinyl Alcohol Coated Membrane for Crude Clove Oil Purification", Periodica Polytechica Chemical Engineering, 64(3), pp. 304-319, 2020. https://doi.org/10.3311/PPch.13871

[19] Sulaiman, N. A., Hassan, A. R., Rozali, S., Mohd Safari, N. H., Takwa, C. W. I. C. W., Mansoor, A. A. D. K., Md Saad, M. H. "Development of Asymmetric Low Pressure Reverse OsmosisSurfactants Membrane: Effect of Surfactant Types and Concentration", Periodica Polytechnica Chemical Engineering, 64(3), pp. 296-303, 2020. https://doi.org/10.3311/PPch.13327

[20] Li, H., Song, J., Tan, X., Jin, Y., Liu, S. "Preparation of spiral porous stainless steel hollow fiber membranes by a modified phase inversion - sintering technique", Journal of Membrane Science, 489, pp. 292-298, 2015.

https://doi.org/10.1016/j.memsci.2015.04.037

[21] Hassan, A. R., Che Wan Takwa, C. W. I., Mohd Safari, N. H., Rozali, S., Sulaiman, N. A. "Characterization on Performance, Morphologies and Molecular Properties of Dual-Surfactants Based Polyvinylidene Fluoride Ultrafiltration Membranes", Periodica Polytechnica Chemical Engineering, 64(3), pp. 320-327, 2020. https://doi.org/10.3311/PPch.13862

[22] Wang, W., Xu, H., Chen, J., Shen, Y., Bertóti, I., Guo, X., Shi, X., Elsiddig, Z. A. "Structure, Mechanical and Electrochemical Properties of Thermally Reduced Graphene Oxide-poly (Vinyl Alcohol) Foams", Periodica Polytechnica Chemical Engineering, 62(1), pp. 8-20, 2018. https://doi.org/10.3311/PPch.11148 
[23] Habibi, S., Nematollahzadeh, A. "Enhanced water flux through ultrafiltration polysulfone membrane via addition-removal of silica nano-particles:Synthesis and characterization", Journal of Applied Polymer Science, 133(25), Article number: 43556, 2016. https://doi.org/10.1002/app.43556

[24] Li, L., Hou, J., Ye, Y., Mansouri, J., Chen, V. "Composite PVA/ PVDF pervaporation membrane for concentrated brine desalination: Salt rejection, membrane fouling and defect control", Desalination, 422, pp. 49-58, 2017. https://doi.org/10.1016/j.desal.2017.08.011

[25] Selim, A., Tóth, A. J., Haáz, E., Fózer, D., Mizsey, P. "Pervaporation Performance of Ag-PVA Nanocomposite Membranes: Effect of Operating Temperature", Periodica Polytechnica Chemical Engineering, 64(1), pp. 85-92, 2020. https://oi.org/10.3311/PPch.13809

[26] Alexandre, V. M. F., de Cerqueira, A. C. F. P., Santiago, V. M. J., Cammarota, M. C. "Bioproducts for Sludge Reduction in Activated Sludge Systems Treating Oil Refinery Wastewater", Oil GAs Science and Technology, 71(2), Article number: 28., 2016. https://doi.org/10.2516/ogst/2015002

[27] Igbinigun, E., Fennell, Y., Malaisamy, R., Jones, K. L., Morris, V. "Graphene oxide functionalized polyethersulfone membrane to reduce organic fouling" Journal of Membrane Science, 514, pp. 518-526, 2016. https://doi.org/10.1016/j.memsci.2016.05.024

[28] Kusworo, T. D., Aryanti, N., Qudratun, Q., Tambunan, V. D., Simanjuntak, N. R. "Development of antifouling polyethersulfone (PES)-nano zno membrane for produced water treatment", Journal Teknologi, 80(3-2), pp. 9-15, 2018. https://doi.org/10.11113/jt.v80.12729

[29] Ahmad, A. L., Sugumaran, J., Shoparwe, N. F. "Antifouling Properties of PES Membranes by Blending with zno Nanoparticles and NMP-Acetone Mixture as Solvent", Membranes, 8(4), Article number: 113., 2018. https://doi.org/10.3390/membranes8040131

[30] Gao, H., Sun, X., Gao, C. "Antifouling polysulfone ultrafiltration membranes with sulfobetaine polyimides as novel additive for the enhancement of both water flux and protein rejection", Journal Membrane Science, 542, pp. 81-90, 2017. https://doi.org/10.1016/j.memsci.2017.07.053

[31] Sarihan, A., Eren, E., Eren, B., Erdoğan, Y. "Flux-enhanced polysulfone membranes blended with ABPBI as a novel additive", Materials Today Communications, 20, Article number: 100594, 2019 .

https://doi.org/10.1016/j.mtcomm.2019.100594

[32] Zangeneh, H., Zinatizadeh, A. A., Zinadini, S. "Self-cleaning properties of L-Histidine doped TiO2-CdS/PES nanocomposite membrane: Fabrication, characterization and performance", Separation and Purification Technology, 240, Article number: 116591, 2020. https://doi.org/10.1016/j.seppur.2020.116591
[33] Selim, A., Tóth, A. J., Haáz, E., Fózer, D., Mizsey, P. "Comparison of Single and Double-Network PVA Pervaporation Performance: Effect of Operating Temperature", Periodica Polytechnica Chemical Engineering, 64(3), pp. 377-383, 2020. https://doi.org/10.3311/PPch.15214

[34] Abdullah, N., Gohari, R. J., Yusof, N., Ismail, A. F., Juhana, J., Lau, W. J., Matsuura, T. "Polysulfone/hydrous ferric oxide ultrafiltration mixed matrix membrane: Preparation, characterization and its adsorptive removal of lead (II) from aqueous solution", Chemical Engineering Journal, 289, pp. 28-37, 2016.

https://doi.org/10.1016/j.cej.2015.12.081

[35] Zhang, Q., Zhang, C., Xu, J., Nie, Y., Li,S., Zhang, S. "Effect of poly(vinyl alcohol) coating process conditions on the properties and performance of polyamide reverse osmosis membranes", Desalination, 379, pp. 42-52, 2016. https://doi.org/10.1016/j.desal.2015.10.012

[36] Gunawan, F. M., Mangindaan, D., Khoiruddin, K. Wenten, I. G. "Nanofiltration membrane cross-linked by m-phenylenediamine for dye removal from textile wastewater", Polymers Advanced Technologies, 30(2), pp. 360-367, 2019.

https://doi.org/10.1002/pat.4473

[37] Kuvarega, A. T., Khumalo, N., Dlamini, D., Mamba, B. B. "Polysulfone/N,Pd co-doped $\mathrm{TiO} 2$ composite membranes for photocatalytic dye degradation", Separation and Purification Technology, 191, pp. 122-133, 2018. https://doi.org/10.1016/j.seppur.2017.07.064

[38] Nasri, H., Khemakhem, S., Amar, R. B. "Physico-Chemical Study of Coating Formulation Based on Natural Apatite for the Elaboration of Microfiltration Membrane", Periodica Polytechnica Chemical Engineering, 58(2), pp. 171-178, 2014. https://doi.org/10.3311/PPch.7388

[39] Chung, Y. T., Mahmoudi, E., Mohammad, A. W., Benamor, A., Johnson, D., Hilal, N. "Development of polysulfone-nanohybrid membranes using xno-GO composite for enhanced antifouling and antibacterial control", Desalination, 402, pp. 123-132, 2017. https://doi.org/10.1016/j.desal.2016.09.030

[40] Chen, W., Wei, M., Wang, Y. "Advanced ultrafiltration membranes by leveraging microphase separation in macrophase separation of amphiphilic polysulfone block copolymers", Journal Membrane Science, 525, pp. 342-348, 2017. https://doi.org/10.1016/j.memsci.2016.12.009

[41] Meng, F., Zhang, S., Oh, Y., Zhou, Z., Shin, H. S., Chae, S-R. "Fouling in membrane bioreactors: An updated review", Water Research, 114, pp. 151-180, 2017. https://doi.org/10.1016/j.watres.2017.02.006

[42] Soltani Afarani H., Mansourpanah, Y. "Physical surface modification of nanoporous TFC membranes using UV irradiation for water desalting; determination of best conditions", Desalination and Water Treatment, 57(42), pp. 19677-19689, , 2015, https://doi.org/10.1080/19443994.2015.1101716 